\title{
Os trabalhadores Loandas da expedição portuguesa ao Muatiânvua (1884-1888)*
}

\section{The Loandas workers of Portuguese expedition to the Muatiânvua (1884-1888)}

\author{
ELAINE RIBEIRO** \\ Departamento de Ciências Humanas \\ Instituto de Ciências Humanas e Letras \\ Universidade Federal de Alfenas \\ Alfenas (MG) \\ Brasil
}

RESUMO Em 1884, o governo português promoveu uma expedição para a Lunda, no atual nordeste angolano. Chefiada pelo major Henrique de Carvalho, esta expedição contou com o trabalho de homens e mulheres oriundos de diferentes partes da África centro-ocidental, que se revelaram responsáveis, em grande medida, pelo andamento da viagem. Tendo como referência a narrativa desta expedição, produzida por Henrique de Carvalho, o objetivo deste artigo é analisar a atuação destes trabalhadores que ficaram conhecidos como Loandas, considerando as novas formas de exploração do trabalho no pós-abolição do tráfico de escravizados e da própria escravidão em regiões africanas.

* Artigo recebido em: 31/03/2013. Autora convidada.

** Doutoranda em História Social pela Universidade de São Paulo. Contatos: elaine.ribeiro.santos@usp.br; elaine. ribeiro@unifal-mg.edu.br. 
Palavras-chave trabalhadores, Lunda, Henrique de Carvalho

ABSTRACT In 1884, the Portuguese government promoted an expedition to the Lunda, the current northeast Angola. Headed by Major Henrique de Carvalho, this expedition featured the work of men and women from different parts of west-central Africa, which proved to be responsible, in large measure, by the progress of the journey. Taking as reference to the narrative of this expedition, produced by Henrique de Carvalho, the purpose of this article is to analyze the performance of these workers who became known as Loandas, considering new forms of labor exploitation after abolition of slave trade and slavery in African regions.

Keyword workers, Lunda, Henrique de Carvalho

\section{Introdução}

Os libertos do Sr. Andrade arreganhavam uns para os outros sorrisos de contentamento, porque, desde a cena violenta com a filha, não foi aplicado castigo corporal a nenhum deles, o que era com efeito caso digno de excepcionais congratulações; pois, quando ele andava menos preocupado, a pretalhada doméstica sentia-lhe a bengala marcando muito energicamente os compassos do hino do trabalho. ${ }^{1}$

Com o progressivo emprego das formas de trabalho compulsório em Angola, especificamente no período imediatamente posterior ao fechamento dos portos brasileiros para a entrada de escravizados africanos e refletindo a legislação abolicionista lusa, o número de trabalhadores com o estatuto de liberto tendeu a aumentar seguindo a variação do peso de atividades econômicas de determinadas regiões e épocas. Alternâncias que nos permitem perceber os espaços de trabalho dos libertos, mas também uma condição pungente: a liberdade recém-formalizada e a coerção ainda vivenciada, como quase podemos sentir pelo texto da epígrafe. ${ }^{2}$

A partir dos números levantados pelo historiador Roquinaldo Ferreira podemos visualizar a presença destes trabalhadores nas seguintes localidades: até a década de 1850, com maior força no centro-sul angolano,

1 Cf.: MACHADO, Pedro Félix. Cenas de Africa? Romance íntimo. Lisboa: Imprensa Nacional/Casa da Moeda, 2004, p.73 e p.90. Texto escrito em 1892 e que se refere à cidade de Luanda da década de 1860, com seus empacaceiros, feiras sertanejas, casas-fortes gradeadas para os libertos e o bairro de Nazaré.

2 A ambiguidade de tal condição é paradoxal ainda mais que o decreto luso de 1858 já havia retirado "aos senhores o direito de infligir a seus escravos castigos corporaes". Analisamos a legislação abolicionista portuguesa no primeiro capítulo de nossa dissertação de mestrado intitulada: Barganhando sobrevivências: os trabalhadores centro-africanos da expedição de Henrique de Carvalho à Lunda (1884-1888). São Paulo: Universidade de São Paulo, 2010 (História Social, Dissertação de mestrado). 
entre Luanda e Benguela; após este período, nas regiões do norte, como em Ambriz, nos vultosos empreendimentos promovidos por comerciantes do tráfico atlântico que passaram a negociar produtos como óleo de palma, café, borracha e amendoim; e ainda no sul, na região de Moçamedes, na coleta de urzela e nas plantações de algodão desenvolvidas nos anos sessenta, em tempos de guerra civil estadunidense. ${ }^{3}$

No entanto, mesmo com toda a demanda conjuntural, as regiões ao longo do corredor do rio Kwanza, desde o litoral luandense até Golungo Alto, continuaram, por todo o período, a concentrar a maior parte dos libertos: nos anos de 1859 e 1863, os números destes trabalhadores passaram de 2.328 para 6.781, em Luanda, e de 9.483 para 21.182, em Golungo Alto. Tal expansão refletiu o alto número de carregadores empregados no transporte de mercadorias "nas rotas de comércio do litoral com os sertões", além das frentes de trabalho nas plantations de café e de cana-de-açúcar na região do Cazengo. ${ }^{4}$

No caso em específico destas últimas regiões, podemos afirmar que na mesma proporção das necessidades de comerciantes, administradores portugueses e grandes sobas do serviço de carreto estava a rejeição por parte das populações alvos do recrutamento. Nesta circunstância, dentre os motivos de repulsa, além da violência e do desvio dos angariados de suas famílias e de seus trabalhos na agricultura, encontravam-se também as disputas de poder no interior dos sobados.

A relevância de tratarmos deste tema encontra-se, sobretudo, na atuação das populações alvos do recrutamento forçado. Neste sentido, a questão que mais nos interessa são as concepções que norteavam as estratégias de resistência, que - acreditamos - foram formuladas a partir das experiências vividas tanto entre as sociedades africanas quanto nas regiões de autoridade portuguesa.

No trânsito entre uma região e outra, as ações em defesa da autonomia de alguma forma incorporaram as noções de direitos discutidas em torno do debate abolicionista da época, como também absorveram valores próprios dos diferentes grupos centro-ocidentais da África.

No caso das regiões de influência portuguesa, os rumores em torno da legislação abolicionista podem ter estimulado o aumento das fugas, nas décadas de 1840 e 1850, para regiões como a Kissama, de longa tradição de resistência ao poder português. Não sendo uma novidade, esta prática pode ser acompanhada desde meados do século XVIII nos registros de

3 Sobre a formação de Moçamedes na década de 1840 por migrantes portugueses oriundos do Brasil, Madeira e Algarve junto a uma sociedade africana composta de libertos do tráfico, engajados nos trabalhos agrícolas da região, ver: DIAS, Jill. Angola. In: ALEXANDRE, Valentim; DIAS, Jias. Nova História da Expansão Portuguesa: o império africano 1825-1890. Lisboa: Editorial Estampa, v.X, 1998. p.441-446.

4 Para os números apresentados, ver o trabalho de Roquinaldo Ferreira em Dos sertões ao Atlântico: tráfico ilegal de escravos e comércio lícito em Angola, 1830-1860. Rio de Janeiro: Universidade Federal do Rio de Janeiro, 1996, p.72 (História Social, Dissertação de mestrado). 
fugas do serviço de carregador anotados na documentação relativa ao governo de Francisco Inocêncio de Sousa Coutinho. ${ }^{5}$

Além disso, outra prática de resistência que aumentou neste período foi a formação de mutolos - como os quilombos eram chamados - na região de Icolo. Segundo o juiz presidente da Relação de Luanda, estas comunidades representavam um "iminente risco" por existir na época "talvez dois mil negros fugidos nos mutolos, a menos de um dia de viagem da cidade", sendo que eram "outras tantas feras contra seus senhores". Mesmo que o número apresentado dos habitantes dos mutolos possa ter sido superestimado pelo juiz, isto não retira a ideia que subjaz à afirmação: a própria existência dos mutolos e o receio que eles provocavam. ${ }^{6}$

Ou ainda, nos anos de 1860, na região de Moçamedes, as fugas seguidas de revoltas motivadas pelo temor de uma possível retomada do tráfico ilegal, porque "supunham (os trabalhadores) e mesmo diziam que já não Ihes restava dúvida alguma, em como depois de longos anos de serviço, com que - com mais certeza deviam contar, é de serem embarcados para além-mar". ${ }^{7}$

Outros episódios de resistência que podem ser relacionados ao debate abolicionista em vigor são encontrados no texto da representação da Câmara de Luanda, de 1860, entregue ao governador-geral. De cunho mais violento, tratam-se de casos de assassinatos ou tentativas de assassinatos de senhores por parte de seus escravizados: a morte por apunhalamento de "dois cidadãos respeitáveis", Mendonça e Prudêncio, de Luanda; na região de Ambriz, ferimento à bala de "um respeitável decano dos facultativos da província"; o assassinato do comerciante Mota de Kasanje e a tentativa de envenenamento por arsênico da família de um "fabricante" de Luanda, afora "referências sobre escravos que ameaçavam, na rua, diversos transeuntes". ${ }^{8}$

Podemos encontrar também ações de resistência nos anúncios dos jornais angolanos da segunda metade do XIX. Entre eles, destacamos a

5 Para um sumário e análise de parte desta documentação que integra o acervo Lamego, guardado pelo Instituto de Estudos Brasileiros da USP, ver: MACHADO, Mônica Tovo Soares. Angola no período pombalino: o governo de Dom Francisco Inocêncio de Sousa Coutinho (1764-1772). São Paulo, Universidade de São Paulo, 1998, p. 48 (História Social, Dissertação de mestrado). Sobre as tentativas frustradas dos portugueses, desde o século XVI, em dominar a região imediatamente ao sul de Luanda, onde havia, para o comércio de longa distância da África Centro-Ocidental, importantes minas de sal, controladas pelas populações que foram registradas nas fontes portuguesas como quissamas, ver: BIRMINGHAM, David. Trade and conflict: the Mbundu and their neighbours under the influence of the Portuguese, 1483-1790. Oxford: Clarendon Press, 1966.

6 Cf.: Luís José Mendes Afonso ao Ministro da Marinha, 22 de abril de 1860, Apud MARQUES, João Pedro. Quatro assassinatos e um retrocesso: violência escrava em Angola (1860-61). In: Centro de Estudos Africanos da Universidade do Porto (coord.) Trabalho forçado africano: articulações com o poder político. Porto: Campo das Letras, 2007, p.106.

7 Representação dos produtores de urzela de Mossamedes contra o tráfico ilegal de escravos, em 24 de março de 1860, examinada por FERREIRA, Roquinaldo. Dos sertões ao Atlântico, p.85-89.

8 Estas ações mais violentas de resistência de escravizados e libertos foram analisadas de modo diferente pelo historiador João Pedro Marques, que acredita na impossibilidade da interferência dos casos de resistência sobre o avanço do processo abolicionista português. Cf.: MARQUES, J.P. Quatro assassinatos e um retrocesso, p.107. 
história de duas libertas que demonstra a ação consciente instrumentalizada no debate sobre a legislação abolicionista em vigor. ${ }^{9}$

No anúncio de venda publicado n'O Mercantil, de 16 de novembro de 1871, lemos que:

Duas libertas de nome Rosa e Domingas - esta filha d'aquella que foram registradas no tempo da escravidão e que agora passaram à condição de libertas. Domingas - em vida de sua ama, requereu dizendo que não era registrada, perdendo a causa por a dona ter apresentado prova. Portanto os annunciantes vão vender (...) as duas libertas para o pagamento do enterro. ${ }^{10}$

Analisando o anúncio conseguimos saber que a ex-escravizada Domingas tentou lutar por sua liberdade na esfera legal por conhecer disposições da legislação abolicionista.

Pela afirmação de que sua proprietária conseguiu provar que ela havia sido registrada, obtemos a informação que Domingas, no tempo da sua escravização, requisitou ser considerada liberta por não ter sido registrada, algo que só poderia ter se dado a partir do seu conhecimento dos termos do decreto de 14 de dezembro de $1854 .^{11}$

Como não temos acesso a este processo, levantamos a possibilidade deste julgamento ter ocorrido antes da promulgação da lei de 1869 e a ela devessem as condições de libertas de Domingas e de sua mãe em 1871, já que foi esta lei que declarou libertos todos os escravizados sob a condição de trabalharem gratuitamente para seus senhores até $1878 .{ }^{12}$

Esta história contida n'O Mercantil nos leva a considerar que Domingas, de alguma forma, soube da lei de 1854 e lançou mão de uma estratégia na esfera legal com o fim de diminuir o tempo da sua escravidão, já que pelo texto da mesma lei, mesmo que conseguisse provar a falta da sua proprietária de não tê-la registrado, ainda assim teria de "servi-la como liberta" por mais sete anos. Deste modo, levando em consideração as possibilidades de Domingas frente à legislação, vemos que, mesmo sendo mínimas as

9 A possibilidade de encontrarmos casos de resistência nos jornais angolanos foi levantada por CURTO, José C em: Resistência à escravidão na África: o caso dos escravos fugitivos recapturados em Angola, 1846-1876. AfroÁsia, n.33, p.67-86, 2005.

10 Cf.: O Mercantil, 16-11-1871 apud OLIVEIRA, Mario Antonio Fernandes. Aspectos sociais de Luanda inferidos dos anúncios publicado na sua imprensa. Boletim do Instituto de Angola, Luanda, n.19, maio-agosto, 1964, p.49.

11 O decreto impunha aos senhores a obrigação do registro dos escravizados, que em caso de não ser realizado implicava na declaração automática destes à categoria de libertos (artigos 1 e 9). Para o texto do decreto de 1854, ver: CUNHA, Joaquim Moreira da Silva. O trabalho indígena: estudo de direito colonial. 2 ed. Lisboa: Agência Geral do Ultramar, 1954, p.132-135.

12 O decreto de 25 de fevereiro de 1869 instituiu para todos os escravizados o estatuto civil de liberto. Por esta determinação legal, as relações trabalhistas ainda obrigatórias daqueles libertos a partir de então deveriam ser regidas pelas disposições do decreto de 1854 até a supressão total da escravidão, em 1878. A propósito destas relações trabalhistas, as mesmas disposições possibilitaram e generalizaram a venda do serviço dos libertos. Como bem lembrou o historiador João Pedro Marques, "a par de um mercado de escravos, (passou) a haver igualmente um mercado de libertos, o que constituía uma verdadeira aberração numa medida formalmente abolicionista". MARQUES, João Pedro. Uma cosmética demorada: as Cortes perante o problema da escravidão (1836-1875). Análise Social, v.XXXVI, n.158-159, p.230-231, 2001. 
chances, elas não foram descartadas como estratégia de ação em favor da liberdade.

Outra questão intrigante do excerto do Mercantil é ser ele um anúncio de venda. Segundo os estudos de Mário Antonio de Oliveira, depois da lei de 1869, o mais comum entre os patrões era anunciar a oferta de aluguel de serviços dos "seus" libertos como uma forma de obter renda com a transferência temporária de sua capacidade de trabalho. ${ }^{13}$

Neste sentido, Domingas que havia lutado por sua liberdade quando sua proprietária estava viva, encontrava-se naquele momento, em 1871, depois da morte da patroa, enredada na teia da reescravização que poderia envolvê-la em mais um ciclo de trabalho compulsório.

\section{Os 'contratados de Loanda'}

Com relação à situação dos trabalhadores libertos, discutida até o momento, podemos dimensionar a questão, no período posterior à promulgação da abolição total da escravidão em Angola, em 1875, a partir da história de um grupo de doze homens contratados por Henrique de Carvalho para a expedição à mussumba (capital) do Muatiânvua (título da autoridade máxima da Lunda), em 1884.

Como o próprio expedicionário nos dá a conhecer, estes homens e suas famílias na cidade de Luanda vivenciaram como escravizados o período de promulgação e (tentativa de) cumprimento da legislação emancipacionista e, principalmente, experienciaram a ambiguidade das condições de trabalhadores libertos.

Referidos por Henrique de Carvalho como os "contratados de Loanda", ou simplesmente "Loandas", à medida que vão se estreitando as relações destes trabalhadores com o chefe da expedição, ao longo dos quatros anos da viagem, ele foi deixando escapar, cada vez mais, na sua narrativa as histórias de vida destes homens, através de menções aqui, rápidas passagens acolá, num rastro de pegadas deixadas pelas experiências, nem sempre harmoniosas, da vida em caravana. ${ }^{14}$

Os homens contratados foram fotografados e nomeados pelos chefes da expedição (figura 2): Paulo, oriundo de Malanje; Matheus, vindo do Libolo; Manuel, da Jinga; Paulino, da Kisama; Roberto, de Benguela; Cabuíta, de Kimbundo; Marcolino, do Kongo; Narciso, da Lunda; Domingos, de Luanda; Francisco Domingos, de Kasanje; Antônio, de Golungo Alto e Adolpho, do

13 Cf.: OLIVEIRA, Mário Antonio de. Os 'libertos' em Luanda no terceiro quartel do século XIX. In: SANTOS, Maria Emilia Madeira (org.) Primeira reunião internacional de história da África. Relação Europa-África no $3^{\circ}$. quartel do século XIX - Actas. Lisboa: CEHCA/IICT, 1989, p.260.

14 Para a narrativa de viagem referenciada, ver: CARVALHO, Henrique Augusto Dias de. Expedição portuguesa ao Muatiânvua 1884-1888. Descripção da Viagem à Mussumba do Muatiânvua. Lisboa: Imprensa Nacional \& Typographia do Jornal As Colônias Portuguesas, v.l: de Loanda ao Cuango, 1890; v.ll: do Cuango ao Chicapa, 1892; v.III: do Chicapa ao Luembe, 1893; e v.IV: do Luembe ao Calanhi e regresso a Lisboa, 1894 (doravante Descripção). 
Kongo. Assim que aparecem nos relatos vão surgindo informações sobre suas famílias, suas qualidades profissionais, suas aspirações e comportamentos, que permitem ao historiador contemporâneo compreender suas noções de direitos e deveres.

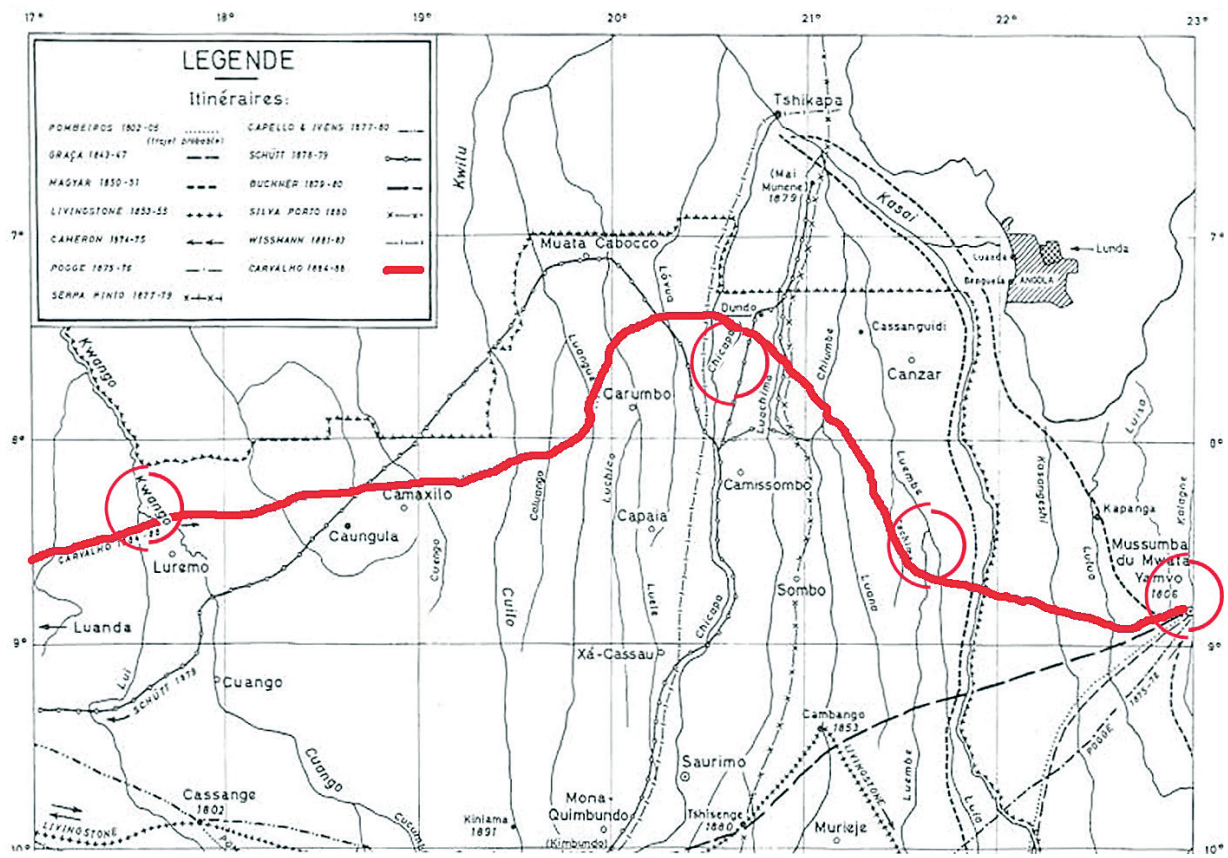

Figura 1. Itinerário da viagem de Henrique de Carvalho à Mussumba do Muatiânvua.

Adaptado de BASTIN, Marie-Louise. Art décoratif Tshokwe. Lisboa: Cia dos Diamantes de Angola, 1961.15

Esta proveniência heterogênea do grupo foi vista com bons olhos pelo chefe da expedição, pela possibilidade de obter informações de diferentes localidades pelas quais a expedição iria passar: "alguns filhos de Malanje, um das próprias terras da Lunda, e dois que dão conhecimento e informações de rios e povoados até além do Cassai". ${ }^{16}$

15 O percurso da expedição de Henrique de Carvalho à Lunda seguiu desde Luanda, passando pelos rios Kwanza e Kwango até a região do Chicapa e de lá até o Luembe e, finalmente em seguida, a mussumba (capital) do Muatiânvua (senhor das riquezas).

16 Cf.: CARVALHO, Henrique A. D. Descripção, v.l, p.65. 


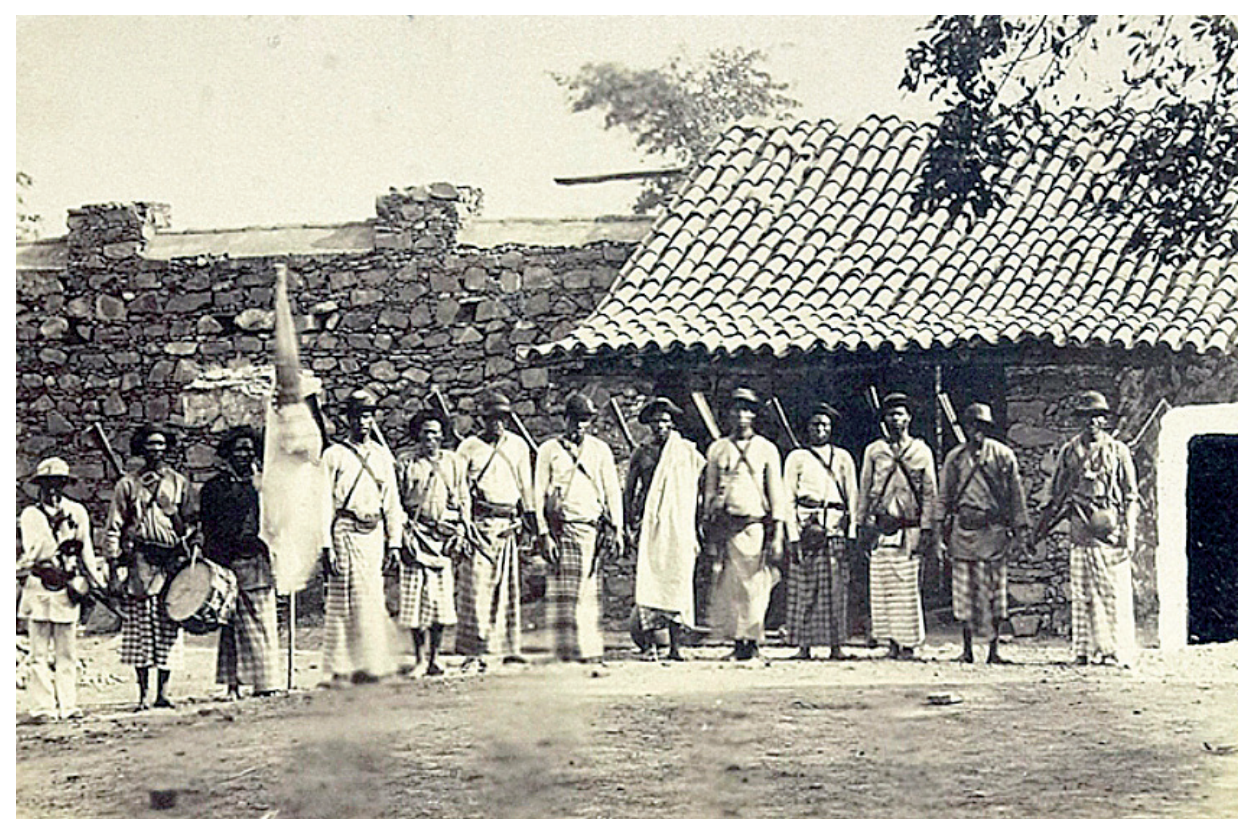

Figura 2. Trabalhadores Loandas.

Álbum da Expedição Portuguesa ao Muatiânvua, 1884-1888.17

\section{Os contratos}

Sabemos, a partir do relato da expedição, que o primeiro contato dos trabalhadores Loandas com Henrique de Carvalho não se deu em junho de 1884, quando este preparava os provimentos e a contratação de pessoal para a viagem à Lunda, mas em anos anteriores, quando o então major era o engenheiro-militar responsável pela construção do hospital Maria Pia, na cidade de Luanda.

Nesta obra, os Loandas trabalharam no transporte de cargas entre a alfândega da cidade e o local da construção e prestaram serviços como carregadores de maxila. ${ }^{18}$ Esta experiência anterior foi considerada positiva, já que Henrique de Carvalho defendeu, em correspondência ao secretáriogeral do governo de Angola, a contratação destes homens, escolhidos de

17 A lista dos nomes dos contratados não está necessariamente conforme a posição das pessoas mostradas na imagem. Como não é possível ter certeza nesta questão, adotamos a ordem dos nomes da forma como foram apresentados por Henrique de Carvalho no seu relato. A décima terceira pessoa talvez possa ser ou o corneteiro Domingos, originário de Massangano, ou o cozinheiro José, do Libolo, que foram contratados juntos com o grupo dos doze. Imagem em: Álbum da Expedição Portuguesa ao Muatiânvua. Disponível em: < http://henriquedecarvalho. bnportugal.pt/fotos/foto116.htm>. Acesso em: 01 dez. 2012.

18 Maxila era o "palanquim ou cadeirinha suspensa de um bordão ou bambú com tampo e cortina" utilizada no transporte de pessoas. Cf.: ASSIS JR., António de. Dicionário Kimbundu-Português. Linguístico, Botânico, Histórico e Corográfico seguido de um índice alfabético dos nomes próprios. Luanda: Argente, Santos e Cia Ltda., s.d. 
um grupo de trinta que se apresentou para os trabalhos da expedição, pela confiança que depositava neles. ${ }^{19}$

Nesta mesma correspondência, Henrique de Carvalho pediu ao secretário-geral uma autorização para proceder ao registro do contrato de trabalho na administração do concelho da cidade, porque mesmo com a confiança declarada, ele também dizia se prevenir contra um não cumprimento dos termos do contrato. "Caso algum d'esses individuos, depois de ter recebido os adeantamentos, deixasse de embarcar, ou fugisse de qualquer ponto para esta cidade".

Precaução que provavelmente foi compartilhada pelos Loandas: o registro do contrato em repartição pública, não só garantia os seus direitos de trabalhadores, algo que no decorrer da viagem pudesse Ihes servir como instrumento de barganha, como reconhecia a sua condição de livres.

Em época de pós-abolição, outro sentido tomado por este contrato de trabalho foi o propagandístico, como escreveu Henrique de Carvalho:

Fazemos referencia especial aos contractos que celebramos, para que se conheçam mais algumas provas sobre o modo por que nos entendemos com os indígenas, e acabe para sempre a idea de que nas nossas possessões se tolera um vislumbre sequer de escravatura. ${ }^{20}$

O contrato de trabalho dos Loandas foi registrado em 09 de junho de 1884, no livro II dos Termos Diversos do mesmo ano, às folhas 22 e 23, pelo administrador Antonio Urbano Monteiro de Castro e confirmado por testemunhas. ${ }^{21}$

Os termos deste contrato, no que se refere às obrigações dos Loandas, exigiam deles o serviço de vigia e defesa das cargas e dos expedicionários, mais eventuais trabalhos de carregadores, "sempre que por falta de pessoal assim se tornasse preciso", além de ser destacado o comprometimento destes homens de "acompanharem a Expedição até a mussumba do Muatiânvua". Tal obrigação dizia respeito ao tempo de duração do contrato que equivalia ao período de dois anos previstos para a realização da viagem.

Estimativa que não se cumpriu, já que o período total da expedição foi de quatro anos, entre junho de 1884 e março de 1888, e assim houve um acréscimo de tempo de trabalho para a maior parte dos Loandas que não só foi até a mussumba do Kalani, como retornou com Henrique de Carvalho à Luanda, sendo que um deles, Antônio, o acompanhou até Lisboa. ${ }^{22}$

19 Sobre a escolha dos doze Loandas, "conhecidos do chefe e que lhe inspiravam mais confiança", ver: CARVALHO, Henrique A. D. Ofício ao secretário-geral do Governo Geral da Província de Angola, Carlos d’Eça de Queiróz, de 07 de junho de 1884. In: CARVALHO, Henrique A. D. Descripção, v.l, p.65

20 Para tanto, ver: CARVALHO, Henrique A. D. Descripção, v.l, p.66.

21 Cf.: CARVALHO, Henrique A. D. Descripção, v.l, p.66.

22 Cf.: CARVALHO, Henrique A. D. Descripção, v.IV, p.732. 
Sem contar o acréscimo do tempo de trabalho, pelas obrigações iniciais o chefe da expedição comprometeu-se a pagar 100 (cem) réis por cada dia de serviço e mais o equivalente a 100 (cem) réis diários para rações, sendo que estas "principiavam vencer do Dondo em diante". Sobre o contrato em geral, Henrique de Carvalho o considerou vantajoso, além da "garantia que oferecia, por ter sido feito na administração do concelho, também pelo lado financeiro". 23

Acerca do valor da remuneração prometida aos Loandas, o major português comparando-o ao salário regular dos maxileiros luandenses, que era de $5 \$ 000$ a $6 \$ 000$ réis mensais (ordenado e ração), reconheceu que a real vantagem dos primeiros era por "Ihe terem sido pagos todos os vencimentos juntos no regresso - o que não compensou de certo os perigos a que se expuseram e trabalhos por que passaram", completou - mas também por terem recebido de maneira adiantada $36 \$ 500$ réis para cobrirem as despesas iniciais da viagem, visto que a alimentação só passariam a ter da cidade do Dondo em diante, "e para deixarem alguma cousa a suas famílias". ${ }^{24}$

Outro exemplo comparativo são os salários dos operários que trabaIhavam na construção do hospital Maria Pia: segundo relatório do próprio Henrique de Carvalho, estes eram de 400 réis em dias úteis e foram considerados, na época, como "muito pequenos". 25

Levando em conta somente o salário em réis (sem aquele destinado às rações) de cada um dos trabalhadores, esta quantia de $36 \$ 500$ réis equivalia a 365 dias de trabalho ou a um ano pelo calendário europeu, isto é, compreendia a metade do total dos vencimentos constante em contrato a que cada um tinha direito. Ainda que o expedicionário não mencione, não é nenhum despropósito aventar que tal feita fosse uma requisição dos próprios Loandas, visto que permaneceriam por muito tempo longe de suas casas. ${ }^{26}$

Talvez possamos entender um pouco mais sobre o valor destes salários relacionando-os com os preços de serviços e mercadorias da época. Por exemplo, ao contratar os Loandas, Henrique de Carvalho teve que pedir ao governador-geral que custeasse a viagem destes trabalhadores nos vapores que percorriam o rio Kwanza, de Luanda até o Dondo. Na ocasião, as passagens dos vapores da Companhia do Cuanza custavam 5 mil réis,

23 Cf.: CARVALHO, Henrique A. D. Descripção, v.l, p.66.

24 Cf.: CARVALHO, Henrique A. D. Descripção, v.l, p.66-67.

25 Cf.: CARVALHO, Henrique Augusto Dias de. Relatório apresentado pelo major Henrique de Carvalho ao diretor das obras públicas da província de Angola acerca da construção do Hospital Maria Pia, incluindo anexos documentais, de 01 de junho de 1881. In: . Expedição Portuguesa ao Muatiânvua. Meteorologia, Climatologia e Colonização: estudos sobre a região percorrida pela expedição comparados com os dos benemeritos exploradores Capello e Ivens e de outros observadores nacionaes e estrangeiros: modo practico de fazer colonisar com vantagem as terras de Angola. Lisboa: Typ. do jornal "As Colonias portuguezas", 1892, p.121.

26 No $4^{\circ}$ volume da Descripção, no capítulo que Henrique de Carvalho procede ao levantamento das despesas de toda a viagem, há uma marcação sobre o valor deste adiantamento ter sido de 478 mil réis, o que dá a entender que a soma de $36 \$ 500$ foi paga a cada um dos doze, embora o total devesse ser de 438 mil réis - um erro de impressão? Para tanto ver: CARVALHO, Henrique A. D. Descripção, v.IV, p.761. 
as de terceira classe, e 10 mil réis, as de primeira; isto significava que se os Loandas quisessem viajar por conta própria nestes vapores, levando em consideração o salário acordado no contrato, teriam que desembolsar o equivalente a cinquenta dias de trabalho para pagarem a passagem da classe inferior. ${ }^{27}$ Sobre a viagem, devido aos preços cobrados pelas passagens, Henrique de Carvalho criticou as péssimas condições do transporte. ${ }^{28}$ Se até mesmo o expedicionário considerou o preço das passagens elevado, talvez para uma melhor compreensão do valor da remuneração dos Loandas, a comparação devesse ser realizada com o valor de outros produtos: os tecidos comercializados em Malanje, em agosto de 1884, no período que a expedição teve de permanecer estacionada na região por falta de carregadores para prosseguir a viagem até a Lunda.

Na ocasião, conforme apurou o chefe da expedição, os riscados azul em branco de primeira, segunda e terceira qualidades eram vendidos, respectivamente, a $3 \$ 000,2 \$ 500$ e $1 \$ 500$ réis a peça. Outros preços de tecidos diferentes eram: para os algodões de $1^{a}, 2^{a}$. e $3^{a}$ qualidades, com distinção de largo e estreito, de $1 \$ 300$ a $3 \$ 500$ réis; para as chitas, classificadas em finas e de negócio, adamascadas e riscadas com cores vivas, que variavam em preço, por peça, de $2 \$ 250$ a $5 \$ 000$ réis e para o riscado anilado - "de que os pretos gostam" - a $4 \$ 000$ réis a peça. ${ }^{29}$ Portanto, estes tecidos eram um tanto custosos para os Loandas que, se pretendiam adquirir alguma peça, deveriam entregar na sua compra, no mínimo, o correspondente a treze dias de trabalho. ${ }^{30}$

\section{Hierarquização dos papéis na Expedição}

Considerando todo o trabalho que os Loandas tiveram durante a viagem, provavelmente mais interessante é confrontarmos seus salários com os de outros membros da própria expedição, porque pode nos permitir perceber possíveis hierarquias internas, provenientes de noções que envolviam a

27 A questão matemática neste caso é simples: 5 mil réis do valor da passagem dividido por 100 réis ao dia de salário é igual a cinquenta dias de trabalho. O pedido de passagens no vapor da Companhia de navegação do Cuanza para os 12 trabalhadores pode ser encontrado no ofício supracitado de Henrique de Carvalho ao secretário-geral Carlos d'Eça de Queiróz, publicado em: CARVALHO, Henrique A. D. Descripção, v.l, p.65.

28 "Nos vapores da companhia do Cuanza só se faz distincção de duas classes. A superior differe da inferior em a primeira ter comida e a outra não; em nos offerecer, para nos deitarmos, as taes camas de campanha sobre o convez, emquanto que na inferior serve de leito o próprio convez; em proporcionar uma bacia e uma toalha para os passageiros mais abonados, e aos demais apenas uma celha. Por taes commodidades paga o passageiro de primeira classe $10 \$ 000$ réis, e o da segunda $5 \$ 000$ réis! (...)

Ora devemos confessar que tudo isto é exhorbitante, e que se por qualquer circumstancia, o que succede muitas vezes, a viagem se prolonga até cinco ou mais dias, torna-se um martyrio para os passageiros de $1^{\mathrm{a}}$ classe pelos incommodos, falta de asseio e mau passadio; e para os da inferior pelo que ainda é peor - a fome!" Cf.: CARVALHO, Henrique A. D. Descripção, v.l, p.89-90.

29 Cf.: CARVALHO, Henrique A. D. Descripção, v.l, p.329-332.

30 Outros produtos também vendidos em Malanje no mesmo período eram as armas lazarinas a $3 \$ 500$ réis a peça "de pau pintado a vermelho, de pederneira, que ahi (no Porto) custam 600 réis" e a pólvora, vendida a 900 réis o barril. Cf.: CARVALHO, Henrique A. D. Descripção, v.l, p.329-332. 
especialização e a importância das funções para o desenvolvimento da viagem.

Como no caso dos salários do cozinheiro José, do Libolo, e do corneteiro Domingos, de Massangano, ambos contratados em Luanda junto com os outros doze e que recebiam um total mensal, respectivamente, de dez mil e cinco mil réis. Se levarmos em conta que nesta soma também estavam inclusos os 100 réis diários para o custeio da alimentação, tal como acontecia com os Loandas, em um mês o ordenado real do primeiro era de sete mil réis e do segundo dois mil réis.

Em uma hierarquização dos papéis dentro da expedição, isto equivale dizer que o trabalho do cozinheiro, responsável direto pela alimentação de Henrique de Carvalho, era mais valorizado; já o segundo, o corneteiro teve seu trabalho menos reconhecido em relação ao dos Loandas, responsáveis pela segurança da expedição. ${ }^{31}$

Outras funções mais bem valorizadas, principalmente pela chefia da expedição, eram a de intérprete e guia que pressupunham um conhecimento aprofundado das regiões além-Kwango e junto a isso, por vezes, a prática da escrita em língua portuguesa. Como no caso do sertanejo Vieira Carneiro, "africano de 50 e poucos anos e empregado como escriturário de comércio na vila de Caculo", região do Cazengo, que se ofereceu para acompanhar a expedição, com a condição do governo garantir-lhe uma pensão para a família no caso de sua morte.

Embora não pudesse prometer a pensão, Henrique de Carvalho estava disposto a pagar-Ihe "transporte, mesa, barraca e uma mensalidade de $18 \$ 000$ réis", isto é, levando em consideração ordenado e alimentação, três vezes mais o valor pago aos Loandas, afora os objetos mencionados, a barraca, a mesa para escrita e a rede, incluída no oferecimento do transporte, que deveria ser levada, pelo menos, por dois homens, o que configurava uma posição social diferente com relação aos outros contratados da expedição.

Assim, com relação a este último ponto, da visibilidade perante o grupo de pertencimento e para além das questões materiais que os valores salariais suscitam, possivelmente tão importante seja aquilo que a historiadora Jill Dias chamou de "sentido subjetivo da diferença": atributos físicos como vestuário, adornos corporais, objetos portados e práticas costumeiras que em termos de identificação social são determinantes. ${ }^{32}$

31 A função do corneteiro era conduzir a expedição pelos caminhos, porque seguia à frente da caravana e influenciava com sua música "no ânimo dos carregadores, que iam levando as cargas e seguindo, sem que fosse preciso dizer-Ihes que avançassem". Esta função o corneteiro comumente compartilhava com o porta-bandeira e o tocador de tambor. Ver: CARVALHO, Henrique A. D. Descripção, v.I, p.107.

32 Sobre esta perspectiva de análise, ver a discussão de Jill Dias sobre os canoeiros vilis da costa do Loango em: DIAS, Jill. Novas identidades africanas em Angola no contexto do comércio atlântico. In: BASTOS, Cristina; ALMEIDA, Miguel Vale de; FELDMAN-BIANCO, Bela (orgs.) Trânsitos coloniais: diálogos críticos luso-brasileiros. Campinas: Editora da Unicamp, 2007, p.317 e p.319. 
Ainda sobre os motivos de Vieira Carneiro em querer acompanhar a expedição, vontade que não se concretizou, talvez por não the ter sido atendido o pedido da pensão, o chefe da expedição anotou:

\begin{abstract}
Contou-nos ele que a sua ultima viagem fora em 1874. Levava muito negocio e roubaram-Ihe quase tudo o que trouxera, resultado de uma boa permutação; sendo forçado a enterrar o resto do marfim, antes de chegar ao Cuango, com receio de que os Bângalas Ih'o roubassem também. Era este o motivo principal por que se propunha a ir comnosco, embora com pequeno salario. Queria aproveitar a passagem da Expedição no regresso, para á sombra dela trazer a sua pequena fortuna. ${ }^{33}$
\end{abstract}

Talvez o mesmo possa ter ocorrido com o cozinheiro José, que mesmo com o salário um pouco maior que o dos outros com quem foi contratado, não permaneceu trabalhando na expedição. Quem sabe tenha ele utilizado a expedição para chegar a algum local que de outra forma não conseguiria acessar? Ou tenha simplesmente fugido quando sentiu a oportunidade? Embora não consigamos entender a circunstância da partida de José, através do relato de Henrique de Carvalho, em outubro de 1884 (quase quatro meses depois da saída da cidade de Luanda), já havia um substituto do cozinheiro do major português, o Loanda Marcolino, que a partir de então passou a ser referido pelo chefe da expedição como "o nosso cozinheiro". ${ }^{34}$

Originário do baixo Kongo, Marcolino foi escravizado ainda criança e trazido para Luanda. Na época de sua contratação para a expedição à Lunda, com a abolição já promulgada, vivia nos arredores da cidade como lavrador junto de sua mulher que era quitandeira no comércio da região. Para compor o ganho de sua sobrevivência, Marcolino ocasionalmente prestava serviços na alfândega e provavelmente foi em uma destas ocasiões que conheceu o major português.

Junto com o Loanda Antônio, Marcolino foi um dos mais próximos de Henrique de Carvalho, acompanhando-o até a mussumba do Muatiânvua e retornando com ele à Luanda. Conhecedor das iguarias do sertão e da sociedade cristã, Marcolino cozinhou para o chefe da expedição desde bombós, infunde, quizacas, ${ }^{35}$ mocotós ${ }^{36}$ e até um galo para a ceia do natal de $1886 .{ }^{37}$ Como também foi a pessoa que Henrique de Carvalho mais

33 Cf.: CARVALHO, Henrique A. D. Descripção, v.l, p.116-117.

34 Cf.: CARVALHO, Henrique A. D. Descripção, v.l, p.381-382.

35 Sobre o preparo destes pratos Henrique de Carvalho, muito provavelmente por ter observado Marcolino, fez anotações detalhadas para o seu estudo etnográfico dos povos Lundas: cf.: CARVALHO, Henrique A. D. Expedição portuguesa ao Muatiânvua: ethnographia e história tradicional dos povos da Lunda. Lisboa: Imprensa Nacional, 1890, p.466-467

36 Como na mesma ocasião no Kafúxi de Sé Quitari, quando Marcolino "estava alegrote e entreteve a sociedade local cozinhando os mocotós para o nosso almoço do dia seguinte". Cf.: CARVALHO, Henrique A.D. Descripção, v.l, p.382.

37 Sobre a ceia de natal, Henrique de Carvalho registrou: "Devido aos cuidados de Marcolino, á meia noite em ponto, saboreava uma explendida canja de gallo, em que o arroz era substituido por milho, que primeiro tinha sido migado num almofariz de madeira". Sobre o ano novo: "Entendera Marcolino, ao uso de Loanda, preparar-me 
confiou nas travessias de rios e pântanos, sendo Marcolino o seu guia de passos nos caminhos difíceis, como na passagem do rio Lúto, que o chefe da expedição teve que atravessar:

Debaixo d'uma imponente chuva, sobre uma pessima ponte quasi sempre coberta d'agua, um amontoado de paus muito tortuosos, que a força da corrente ia deslocando pouco a pouco, de modo que eu tive de ser guiado á mão, por Marcolino que ia na frente, indicando-me os paus firmes em que podia assentar os pés e, de quando em quando, encontrava-me em grandes embaraços para passar as pernas, sobre os paus levantados e moveis. ${ }^{38}$

Conforme a viagem foi acontecendo, a proximidade das relações fez com que Henrique de Carvalho externasse ainda mais a sua admiração por aquele que considerou estar entre a "nata dos cozinheiros". ${ }^{39}$

Junto com estas práticas cotidianas, que permitiram aos Loandas, por sua proximidade com o chefe Henrique de Carvalho, uma maior visibilidade entre os diferentes grupos de trabalhadores, outros elementos também fizeram com que a expedição como um todo se destacasse na paisagem social como uma sociedade expedicionária, cujo chefe era o major português.

\section{Os filhos de muene puto e as novas insígnias de poder}

Joseph Miller, ao estudar a constituição do poder político e sua relação com o sistema de parentesco entre os Mbundu da África Centro-Ocidental, apontou para a possibilidade de se perceber o sistema de parentesco como um sistema social cuja essência diz respeito a uma ligação dos vivos com os antepassados mortos há muito tempo e que está "para além da formação de novos conjuntos populacionais devido a fatores migratórios". ${ }^{40}$

Neste sentido, uma das formas deste movimento histórico pode estar naquilo que Miller chamou de instituições transversais ao sistema de parentesco, isto é, a existência de associações capazes de transcender o poder genealógico das sociedades hierarquizadas pela forma do parentesco e que, para os nossos propósitos, são capazes de dimensionar o significado de trabalho para as sociedades da África centro-ocidental, para além da questão da subsistência humana.

uma refeição á meia noute, para o que tinha contribuido Rocha com uma gallinha; queria que me despedisse do anno de 1886". In: CARVALHO, Henrique A.D. Descripção, v.IV, p.189 e p.224.

38 CARVALHO, Henrique A.D. Descripção, v.IV, p.555. Ou ainda, quando na vez que levou o major nos ombros, v.II, p.400, ou quando este ficou contrariado porque teve que ir com outra pessoa por Marcolino não ter chegado a tempo da travessia dos riachos Hongo e Liba, v.IV, p.430-433.

39 Cf.: CARVALHO, Henrique A.D. Descripção, v.IV, p.46. Para a imagem de Marcolino com sua mulher, ver: Álbum da Expedição Portuguesa ao Muatiânvua. Disponível em: < http://henriquedecarvalho.bnportugal.pt/fotos/foto190. htm\# > . Acesso em: 01 dez. 2012.

40 Cf.: MILLER, Joseph. C. Poder político e parentesco: os antigos estados Mbundu em Angola. Luanda: Arquivo Histórico Nacional/Ministério da Cultura, 1995, p.29. 
Neste caso, o trabalho seria uma relação que se dá em tempo e espaço determinados e que necessitaria de ser formalizado por uma ritualização e o porte de símbolos e marcas enquanto forma de coesão social.

No seu estudo, Joseph Miller discute ainda quando esta forma do trabalho passa a se constituir um mecanismo de poder capaz de contestar a legitimidade da autoridade instituída sob o sistema de parentesco. Exemplificado na associação de mestres-caçadores (yibinda, singular kibinda) entre os Mbundu, este estudo foi capaz de perceber uma relação entre poder, identidade, competição e conflitos.

Em linhas gerais, na questão identitária, a associação dos yibinda pressupunha a criação de laços pessoais para além das estruturas do parentesco, uma vez que um iniciante (mona a yanga, ou yanga, querendo dizer 'filho do kibinda') na profissão de caçador podia ter como mestre um kibinda que se encontrava fora do seu grupo de parentesco. Deste modo, a relação entre mona e mestre era comparável àquela entre pai e filho, que, no caso Mbundu, atravessava os laços matrilineares entre tio e sobrinho.

Esta relação se baseia na concepção de pai social, aquele que preside o rito de iniciação do novato, que tem o poder de criar uma solidariedade para além das linhagens, formando assim novos segmentos sociais independentes do sistema de parentesco ou dos laços consanguíneos. Grosso modo, este foi o caso dos acampamentos de circuncisão chamados de kilombos dos ovimbundus e adotados posteriormente pelos imbangalas como organização social e política. ${ }^{41}$

Outras formas de manifestação identitária do caçador eram os encontros nas florestas, nas cerimônias em ocasião da morte de um kibinda famoso e os sinais secretos de reconhecimento dos yibinda que faziam com que os laços entre os caçadores se estendessem "muito para além dos limites do parentesco e mesmo da etnicidade". ${ }^{42}$

A possibilidade de haver competição e conflito, ou seja, de existir "uma interferência nas estruturas políticas tradicionais dos Mbundu", deu-se pela transmissão de poder a partir das insígnias como objetos de mediação com as forças espirituais e naturais. ${ }^{43} \mathrm{O}$ exemplo mais destacado por Miller em seu estudo foi a transmissão de poder a partir da insígnia Ngola, "que forneceu mais uma, entre outras, forma de construir laços não hierarquizados pelo parentesco entre linhagens Mbundu". ${ }^{4}$

A partir desta análise do trabalho de Joseph Miller, podemos refletir sobre o caso dos Loandas e outros grupos da expedição que foram reco-

41 Para tanto, ver o capítulo O Kilombo dos Imbangala: uma solução radical, em: MILLER, Joseph C. Poder político e parentesco, p.149-173.

42 Cf.: MILLER, Joseph C. Poder político e parentesco, p.52.

43 Insígnias que por serem símbolos físicos de poder, ao serem conservadas, constituem-se em mais uma fonte histórica destes povos, sem perder de vista a dimensão da transformação por que passaram tais insígnias, já que seu significado e uso variaram conforme o tempo.

44 Cf.: MILLER, Joseph C. Poder político e parentesco, p.63. 
nhecidos pelas diferentes sociedades contatadas ao longo dos caminhos como filhos de muene puto (rei de Portugal ou autoridade máxima dos portugueses). Ou ainda, identificados como filhos do angana ou muata majolo (senhor major) que tinha a seu serviço o nganga dontolo, o subchefe Sisenando Marques, que na qualidade de farmacêutico, por vezes, ministrou remédios aos doentes da expedição. ${ }^{45}$

Assim, os Loandas como ex-escravizados, portanto, desenraizados de suas origens, que eram diversas - do Libolo, da Jinga, da Kisama, de Benguela, de Kimbundo, do Kongo, da Lunda, de Luanda, de Kasanje e de Golungo Alto - no período de pós-abolição encontraram na expedição uma forma de integração social por meio da incorporação de elementos variados, como novas insígnias de distinção social, a partir de experiências múltiplas vividas em conjunto.

\section{As novas insígnias de poder: armas e vestuário}

Tal questão pode estar inserida, por exemplo, no porte de objetos e vestuário que os distinguiam dos demais grupos dos caminhos da expedição: uniformes, correames e armamento que deviam ser utilizados nas "solenidades nas terras dos maiores dirigentes Lundas". Estes atributos físicos eram entendidos por eles como uma espécie de distintivo que lhes possibilitava agir em nome do chefe da expedição.

Não queremos dizer com isso que Henrique de Carvalho foi confundido tal e qual a um chefe político africano tradicional. Quanto a esta ideia, julgamos poder verificar a consciência mais profunda dela, principalmente, entre os Loandas.

No nosso entendimento, a figura de Henrique de Carvalho foi formulada em um sentido próprio ao empreendimento da expedição à Lunda, como uma autoridade capaz de dar um sentimento de unidade grupal em torno de um objetivo que passou a ser comum: chegar a mussumba do Muatiânvua, visto que, sendo todos voluntários, contratados pelo angana major, iriam com ele porque o "majolo lá queria ir". ${ }^{46}$

Assim, na qualidade de testemunhas, a caracterização como gente de muene puto fez sentido nas cerimônias de assinatura dos tratados realizados com as autoridades Lundas ${ }^{47}$ e como emissários nas comitivas para

45 Para o reconhecimento de Henrique de Carvalho como gana majolo e a tradução dos Chokwes do termo mona para muana gana 'senhor filho', ver: CARVALHO, Henrique A.D. Expedição Portugueza ao Muatiânvua: méthodo prático para fallar a língua da Lunda contendo narrações históricas dos diversos povos. Lisboa: Imprensa Nacional, 1890. p.156 e p.290.

46 CARVALHO, Henrique A. D. Descripção, v.IV, p.11.

47 Para a descrição dos ritos e cerimônias realizados nos momentos de leitura e posterior assinatura dos tratados realizados entre Henrique de Carvalho, como representante português, e os dirigentes políticos Lundas, ver o seu: A Lunda ou os estados do Muatiânvua: domínios da soberania de Portugal. Lisboa: Adolpho, Modesto \& Cia., 1890. 
estabelecer os primeiros contatos da expedição com as autoridades locais, quando eram levados presentes ou musapos, ${ }^{48}$ conforme o costume.

Destacável, neste sentido, foram as missões do Loanda Paulo nos acampamentos dos Chokwes, para sossegar os ânimos em tempos de guerra com os Lundas, como também nas visitas às autoridades deste mesmo povo acompanhando Henrique de Carvalho como intérprete ou muzumbo, na linguagem Lunda. ${ }^{49}$

Outro que também se sobressaiu foi o Loanda Antonio, tanto por suas atribuições diárias - cuidados com o armamento da expedição, inclusive da arma pessoal de Henrique de Carvalho, e da segurança das cargas - quanto por seus atributos físicos - o vigor Ihe permitiu, junto com o Loanda Adolpho, entrar no recinto que ia ser fechado por labaredas e salvar dois rapazes -e ainda pelo próprio uso do uniforme encomendado especificamente para vestir os soldados de Ambaca, convocados para servir à expedição, e os trabalhadores contratados em Luanda. ${ }^{50}$

Uniformes que, de acordo com o chefe da expedição,

porque era de justiça vestirmos os soldados e por equidade os contratados de Loanda, para o que havíamos mandado pedir ao nosso correspondente em Malanje fardas encarnadas e bonés de veludinho preto e uns pannos imitando os chamados da Costa ás riscas de diversas cores.

Este uniforme econômico e vistoso reservavamo-lo para servir nas nossas solemnidades nas terras dos maiores potentados. ${ }^{51}$

A importância atribuída ao uniforme nas relações sociais da expedição também funcionou nos casos de punição: como no rebaixamento do soldado Cambuta, "o de pequena estatura", a carregador, por causa de uma briga que se envolveu com os shinjes, por ter sido chamado de "escravo de Muene Puto" pelo chefe da povoação, Mona Candala. Sobre a punição, inclusive com castigo corporal, Henrique de Carvalho anotou:

Tinhamos de ser inexoráveis, e ordenámos ao cabo da força para que immediatamente despojasse o delinquente do seu uniforme e lhe desse um panno de carregador a cuja classe passava durante todo o tempo que estivesse ao serviço da Expedição, e ainda que nos custasse, demos ordem para lhe baterem nas costas com correias. Eram então os anganas (shinjes) que nos pediam cessasse com o castigo, e as mulheres e os rapazes nos limites das povoações imploravam

48 Os musapos também eram um modo de adquirir alimentos para os integrantes da expedição: "como a Expedição tem por costume quando chega a qualquer povoação, mandar logo um signal de amizade, musapo (presente) ao soba, este vem agradecer também, trazendo uma vitella ou garrote, se tem gado, maior, quando não um porco ou carneiro, e os menos abastados, galinhas, ovos ou qualquer outra cousa." Cf.: CARVALHO, Henrique A.D. Descripção, v.ll, p.455.

49 CARVALHO, Henrique A.D. Descripção, v.IV, p. 45, p.360-361, p.450-451, p.462, p.480, p.485

50 Sobre o incêndio ocorrido no acampamento da expedição ver: CARVALHO, Henrique A. D. Descripção, v.ll, p.463464. Sobre os cuidados de Antonio com o armamento e a segurança das cargas, v.IV, p. 174 e p.295.

51 Cf.: CARVALHO, Henrique A.D. Descripção, v.IV, p.487. 
em altos gritos a Muene Puto que perdoasse. O soldado ficou ainda prohibido de sair da cubata emquanto nos demorássemos na Estação. ${ }^{52}$

Portanto, ser filho de muene puto não signicava ser escravo no entendimento dos integrantes da expedição. A razão deste conflito, muito importante para o entendimento da sociedade expedicionária formada, provavelmente se relacionava ao sentido de escravo nas palavras do chefe shinje.

\section{As novas insígnias de poder: a escrita}

Outro aparente aspecto de distinção dos filhos de muene puto foi proporcionado pela possibilidade da aprendizagem da escrita. Desta experiência, ficou-nos a fotografia tirada no acampamento junto ao rio Camau, que mostra o professor cabindense José Faustino (vestido de branco) e o contratado Adolpho (em pé, ao meio), junto com os alunos, todos posando com um papel à mão (Figura 3).

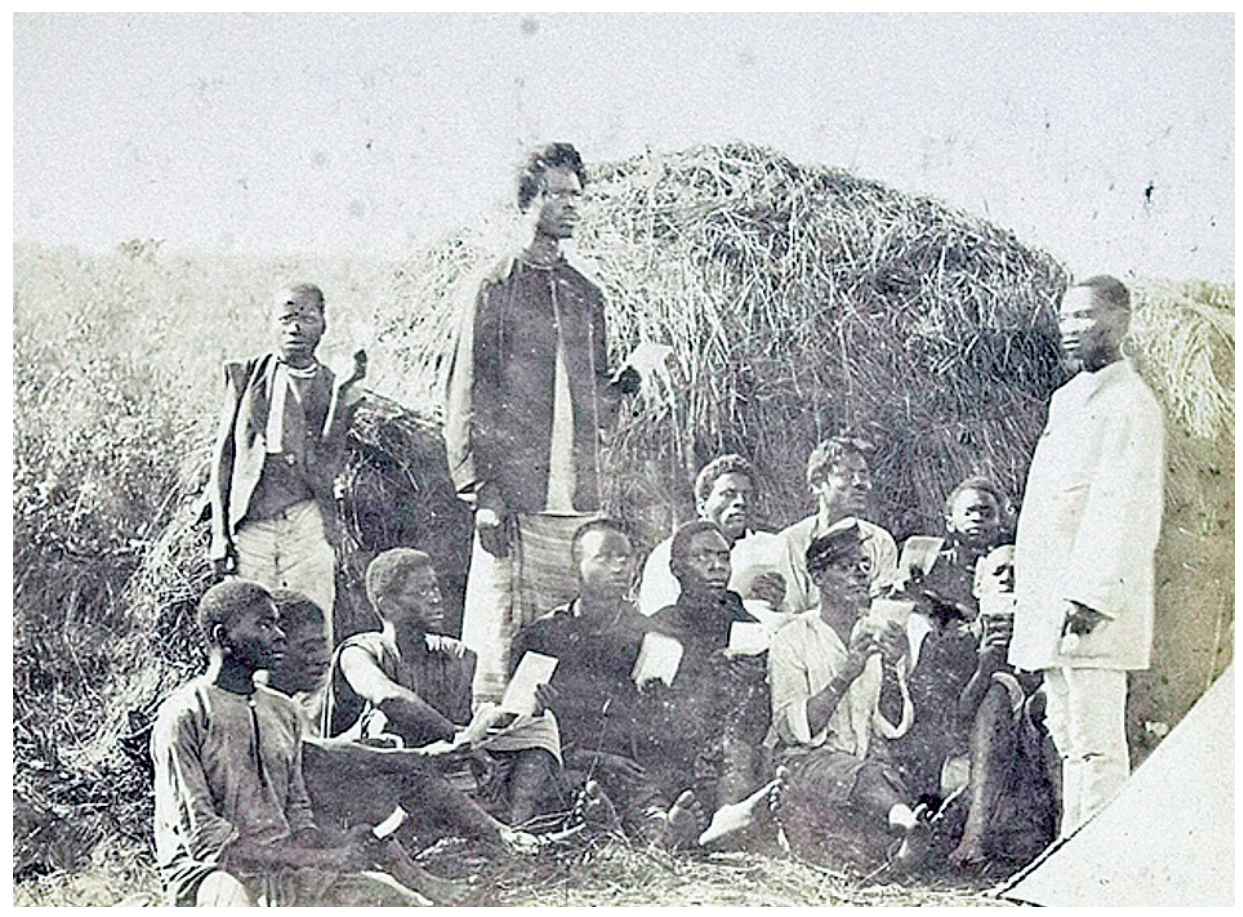

Figura 3. Escola do acampamento. Álbum da Expedição Portuguesa ao Muatiânvua, 1884-1888. ${ }^{53}$ Biblioteca Nacional de Portugal.

52 Cf.: CARVALHO, Henrique A. D. Descripção, v.II, p.129-131.

53 Álbum da Expedição Portuguesa ao Muatiânvua. Disponível em: < http://henriquedecarvalho.bnportugal.pt/fotos/ foto154.htm>. Acesso em: 01 dez. 2012. 
De acordo com o expedicionário Henrique de Carvalho, tratava-se de "uma aula de intrucção primaria - que se instituíra por lembrança do empregado José Faustino e outros, onde concorriam alguns soldados, carregadores de Malanje e menores, a qual continuou durante a viagem, e alguns discipulos teve que aproveitaram". ${ }^{54}$

Entre os que aproveitaram, provavelmente estava o carregador Xavier, que no retorno de toda a expedição ao litoral enviou a Henrique de Carvalho a seguinte carta, pedindo atestado de bom comportamento:

Meu bom patrão. - Desejo-lhe saude. Por este meio venho sollicitar a V. uma fineza que desejo vel a realisada. Como vim a esta cidade (Luanda) em acompanhamento de V., no seu regreço a esta, e como não sou filho d'esta terra e por não me agradar esta terra, não quero ficar, quero regraçar-me á minha patria, portanto venho por meio d'esta minha cartinha, pedir o favor de me passar um escripto do meu bom comportamento durante a longa viagem que fizemos para ir á Mussumba e para chegar a esta cidade, que parece não tinha fim, qual é o meu mau procedimento que procedi na viagem, se assim V. patrão assim julgar, outro sim passar-me uma carta para minha segurança, que quando eu chegar á minha terra não me acontecer nada, porque eu em chegando lá, quero fabricar minha cubata em ordem no caminho do negocio junto á minha familia, para quando vier qualquer auctoridade do Rei como o patrão receber-ia em boa harmonia, eu sou preto mas com o coração de branco. A terra que eu quero fabricar lá no caminho é o Camau, onde o meu patrão com o seu Angananzambi cortou o fogo no acampamento, onde todos iamos ficando assados, portanto peço a $\mathrm{V}$. este obsequio e favor para o meu governo. - Sou com toda a estima de V. Atto. $\mathrm{V}^{\circ}{ }^{\circ} \mathrm{Obr}^{\circ}$. $\mathrm{Cr}^{\circ}$. Servo que pede a resposta (ass.) Xavier Domingos Paschoal. - NB. Não se esqueça de me dar uma bandeira do nosso Rei para a cubata. ${ }^{55}$

Sobre o carregador Xavier e seu pedido o major português afirmou que:

Não era muito exigente e merecia que alguma coisa fizesse em seu beneficio, pois foi um dos que se comportou bem; paguei a sua passagem para o Dondo no vapor da carreira e dei-Ihe seis mil réis em cobre para comer até Malanje. Recebeu uma bandeira nacional com a competente auctorisação para a hastear junto da sua residencia e tambem um attestado de seu bom comportamento, emquanto esteve ao serviço da Expedição, e entreguei-lhe tambem cartas para os chefes dos concelhos e amigos Ihe dispensarem protecção. ${ }^{56}$

E assim, para além da apreensão da escrita, com a carta de Xavier compreendemos o sentimento de injúria do soldado Cambuta: sendo

54 Cf.: CARVALHO, Henrique A.D. Descripção, v.II, p.235

55 Salvo engano de minha parte, não há nenhum reparo, como de costume, do major português que esta carta tenha sido escrita por outra pessoa a pedido de Xavier, portanto, inferimos que ela seja do próprio carregador. Para a carta citada e a gravura de Xavier, ver: CARVALHO, Henrique A. D. Descripção, v.IV, p.722-723. Esta carta foi analisada também no trabalho de HEINTZE, Beatrix. A lusofonia no interior da África Central na era pré-colonial: um contributo para a sua história e compreensão na Actualidade. Cadernos de Estudos Africanos, n.7-8, p.179-207, jul. 2004/ jul. 2005, p.203. Disponível em: <http://cea.iscte.pt/index.php?option=com_docman\&task=doc_view\&gid=73> . Acesso em: 01 out. 2010.

56 Cf.: CARVALHO, Henrique A. D. Descripção, v.IV, p.723-724. 
parte da sociedade expedicionária, nada mais justo que ser reconhecido como filho e não escravo de Muene Puto. Também por isso os pedidos de Xavier, pelos bons trabalhos prestados: uma recomendação por escrito que atestava a sua filiação ao angana major junto às autoridades africanas e uma bandeira portuguesa como insígnia de seu pertencimento. Portanto, assim como Cambuta defendeu sua posição social, Xavier, em favor de seus interesses, operou pela lógica local e não por uma submissão cega ao poder luso.

Ainda com relação à escrita, o empregado José Faustino, que por seu conhecimento das línguas portuguesa e Lunda, teve importante participação na formulação dos tratados realizados entre a expedição e as autoridades locais, conseguiu até mesmo fazer constar em um deles os seus interesses pela escola da expedição:

Com annuencia do Muatiânvua, (a abertura de) uma escola primaria de instrucção da lingua portugueza obrigatoria para todos os menores que faziam parte da Expedição entre sete a quinze annos e para todos os individuos que o Muatiânvua levava na sua comitiva e que elle dizia que ia mandar frequentar. Que por emquanto era professor d'ella o empregado da Expedição José Faustino, que sob sua direcção havia de leccionar das 11 horas da manhã ás 2 horas da tarde, tendo logar a primeira lição no dia 3 do proximo mez (de novembro de 1885) e esta aula, a primeira que se estabelecia em terras da Lunda entendia dever denomina-la Chibunza lanvo (como também se chamava o Muatiânvua eleito) para que pelo menos os seus discipulos se recordasse no futuro, não só d'este dia, como do Muatiânvua presente que de passagem pelas terras do Caungula seguia a chamado dos grandes quilolos a tomar posse do seu Estado. ${ }^{57}$

A adoção de costumes portugueses por parte dos africanos foi relativizada por Conceição Neto em sua crítica ao lusotropicalismo. Como nos exemplos aqui apresentados, das práticas alimentares (as iguarias do sertão junto às da sociedade cristã), do vestuário e da aprendizagem da escrita da língua portuguesa. Se esta adoção significou um processo desestruturante das sociedades africanas, por outro lado e simultaneamente - nas palavras da historiadora - "forneceu possibilidades de mobilidade social vertical",

57 Excerto do tratado da expedição portuguesa com o caungula Muata Xa Muteba, grande quilolo do Muatiânvua, pode ser visto em CARVALHO, Henrique A.D. Descripção, v.ll, p.692. Dentro do contexto imperialista do final do século XIX, de busca por parte dos portugueses de legitimação de poder sobre os territórios africanos, este tratado foi realizado em 31 de outubro de 1885 nas terras do Caungula da Lunda, na confluência entre os rios Mansai e Lóvua. Na ocasião, acompanhava a expedição até a mussumba do Kalani, a comitiva do Muatiânvua eleito conhecido como Xa Madiamba ou Chibunza lanvo. Nesta região - a mussumba do Kalani - reconhecidamente a capital da Lunda, lanvo deveria ser instituído como Muatiânvua (autoridade máxima da Lunda), fato que não aconteceu devido às questões políticas com os Chokwes que também disputavam o cargo. Quando Henrique de Carvalho chegou à mussumba, como Muatiânvua interino estava Mucanza, com que efetivamente realizou um tratado em janeiro de 1887. Para tanto ver: Correspondência de Henrique de Carvalho ao ministério da marinha e ultramar, datada de Luambata, na margem esquerda do Calanhi, de 01 de fevereiro de 1887. In: CARVALHO, Henrique A. D. Descripção, v.IV, p.787-796. 
como nos caso de Marcolino, Antonio, Cambuta, Adolpho, José Faustino, Xavier e outros que pertenceram à sociedade expedicionária.

Por este motivo que a historiadora propõe pensarmos estas absorções culturais para além dos vícios do pensamento lusotropicalista:

\begin{abstract}
Igualmente fruto dos contatos, diretos ou indirectos, com portugueses e outros europeus, foi a introdução nesta parte do mundo da mandioca e do milho, das calças e camisas dos homens, dos 'quimones' e dos panos de algodão dos trajes tradicionais das mulheres, dos canhangulos dos velhos caçadores. E nada disso precisa do 'lusotropicalismo' para ser explicado, manifestando simplesmente o resultado de influências culturais, impostas em diversas circunstâncias ou voluntariamente assumidas. ${ }^{58}$
\end{abstract}

Ainda sob este prisma, a escrita dos trabalhadores da expedição, mais do que se referir à "boa influência lusa" - como por vezes o próprio major português tenta nos fazer crer -, significou uma aceitação de aspectos do exterior que em alguma medida passaram a fazer sentido como atributo de relevância social entre os agentes africanos.

\title{
Uma sociedade expedicionária
}

Outra trajetória que nos permite avançar no entendimento da sociedade expedicionária, e, sobretudo, da configuração identitária dos Loandas como um grupo influente da expedição, é a do contratado Matheus, inclusive naquilo que comumente entendemos ser "mais africano": a liderança dos mais velhos pelo respeito que inspiram.

O velho Matheus, como era conhecido pelos outros trabalhadores, nascido no Libolo, região ao sul do rio Kwanza, foi um dos Loandas que, devido a sua idade, mais vivenciou os efeitos da promulgação da legislação abolicionista portuguesa. Escravizado ainda criança e levado para Luanda, foi comprado pela famosa negociante do trato atlântico, Ana Joaquina dos Santos e Silva. Depois de algum tempo, Matheus foi revendido junto com outros escravizados para uma mulher chamada Thereza. ${ }^{59}$

A partir da Descripção de Henrique de Carvalho, sabemos que o velho Matheus foi carregador de maxila em Luanda, inclusive servindo o major português na sua primeira estadia na cidade, entre os anos de 1878 e $1882 .{ }^{60}$

A estima que o velho Loanda inspirava em diferentes grupos de trabaIhadores da expedição pode ser vista, por exemplo, na narrativa da viagem

58 NETO, Maria da Conceição. Ideologias, contradições e mistificações da colonização de Angola no século XX Lusotopie, p.331-332, 1997. Disponível em: <http://www.lusotopie.sciencespobordeaux.fr/resu9719.html>. Acesso em: 01 nov. 2010.

59 Cf.: HEINTZE, Beatrix. Pioneiros africanos: caravanas de carregadores na África Centro-Ocidental (entre 1850 e 1890). Lisboa: Editorial Caminho, 2004, p.139.

60 Para a fotografia de Mateus junto com duas mulheres e uma criança Lundas, ver: Álbum de fotografias da Expedição. Disponível em: <http://henriquedecarvalho.bnportugal.pt/fotos/foto140.htm>. Acesso em: 01 dez. 2012. 
que Agostinho Sisenando Marques (farmacêutico subchefe da expedição) fez com uma turma de trabalhadores até uma comunidade Chokwe. No momento em que o subchefe ordenou a partida, ele recebeu uma negativa dos homens: "Não podemos, senhor, adoeceu o velho Matheus, e não há de ficar abandonado no mato, respondeu uma voz do grupo". ${ }^{61}$

Nessa ocasião, outro motivo da recusa da marcha também pode ter sido uma espécie de solidariedade entre os grupos que acompanhavam o subchefe, já que Sisenando Marques anteriormente vinha disputando forças com os carregadores massongos. Enfim, não só o velho Matheus como também os outros Loandas, devido às suas atuações, acabaram de pouco em pouco a serem reconhecidos como lideranças por todos que se envolveram com o empreendimento português.

Inclusive pelo chefe Henrique de Carvalho, que já perto da mussumba do Kalani, depois que boa parte da expedição por falta de recursos retornou a Malanje, foi forçado a refletir, com relação aos Loandas e outros trabalhadores mais próximos, sobre o estado de dependência não só da sua própria sobrevivência, como de todo o projeto da expedição portuguesa ao Muatiânvua:

Não direi que esteja completamente só, escrevia eu no Diario, pouco depois de retirarem os meus companheiros, de 28 mezes successivos de trabalhos, no coração d'este continente, porque, enfim, commigo quizeram ficar voluntariamente, o interprete e sua familia, o José Faustino, o Augusto Jayme, os dez contractados de Loanda (inclusive Matheus), o piloto, seis carregadores de Malanje, os meus afilhados Henrique, Mario e Filipe, e essas 156 pessoas da Lunda, que me comprometi a apresentar ás suas familias na Mussumba; porém, o que é muito peor, é que somos 190 bôccas que precisamos comer, e faltam-me os recursos indispensaveis para comprar os alimentos, até para os 26 a que se reduziu a Expedição!

(...)

Mandei chamar de novo, todos os meus companheiros, e fiz-lhes sentir, que pouco era o que tinhamos para comer, que já estavamos na epocha das chuvas, e não podiamos contar com o recurso da caça, e portanto, que todos deviamos esperar o soffrimento da fome. Não eram elles obrigados a arrostar contra mais sacrificios e privações por minha causa, estavam todos muito a tempo de retirarem e alcançarem a Expedição, que se demorava em Calamba Cassênga, fazendo fornecimento de farinhas e de bombós. ${ }^{62}$

Na resposta a estas quase súplicas do chefe da expedição, ao confirmarem o seu propósito de continuar com a expedição, os companheiros de Carvalho fizeram questão de reafirmar o seu estatuto de pessoas livres, já que acentuaram a vontade própria no cumprimento - e diríamos extensão - do contrato acordado com o angana major:

61 Cf.: MARQUES, Agostinho Sisenando. Expedição portugueza ao Muata-lanvo: os climas e as producções das terras de Malange à Lunda. Lisboa: Imprensa Nacional, 1889, p.390.

62 Cf.: CARVALHO, Henrique A. D. Descripção, v.IV, p.8. 
Responderam: somos todos voluntarios, fômos contractados pelo angana major e só regressaremos com nosso amo; se algum de nós morrer, é sorte; a nossa obrigação é acompanhar o angana major á Mussumba, visto que, quer lá ir, e comer para o homem, (o homem era eu) sempre se há de arranjar. ${ }^{63}$

Deste modo, Henrique de Carvalho, frente a esta situação, acabou por expressar, e até de maneira acusatória, parte do que há de implícito em seu discurso colonialista, o reconhecimento e a dependência europeia do trabalho africano:

\begin{abstract}
Bons rapazes; nunca esquecerei as provas de defferencia, que ainda nas occasiões as mais criticas, fiquei devendo a estes meus companheiros!

Que me importa a côr, a sua origem, o seu nascimento, a sua humilde posição, o seu estado social e d'onde vieram! Sei que são homens de sentimentos, que fracos e abatidos pela fome se esforçavam a derrubar palmeiras, para irem em seguida cozinhar os palmitos, ou arrancavam as raízes da terra, até poderem encontrar tuberculos, que coziam em água, para me alimentarem; que além de muitas outras condescendências e considerações de respeito, que individuos esfaimados e desalentados, em regiões civilisadas, só como virtude, por excepção, as podem ter por outrem, eu as tive, de uma abnegação de seus proprios interesses, para me salvarem das vascas da morte, que, quase de mim se ia apoderando, quando já supponha ter terminado a minha missão!
\end{abstract}

Quanto se enganam aquelles que na Europa, compulsando no seu gabinete um ou outro caso isolado, narrado pelos viajantes africanos, d'estes pretendem deduzir que os prêtos são entes desnaturados!64

\title{
Conclusão
}

Em suma, se para Henrique de Carvalho os contratos realizados com os Loandas serviram como defesa contra as acusações feitas por outras nações europeias aos portugueses de práticas escravistas, para homens como Matheus e os outros Loandas, os mesmos documentos significaram, na era ambígua da pós-abolição, o registro da sua situação social enquanto homens livres. Além disso, configurou a eles, no trabalho cotidiano na expedição, uma posição de liderança frente aos outros trabalhadores arregimentados ao longo da viagem.

Assim, é nesta perspectiva que o nosso estudo, ao objetivar recuperar o sentido do trabalho realizado pelos contratados africanos centro-ocidentais que participaram da Expedição portuguesa ao Muatiânvua, acabou por ter que ir além do significado do controle social português.

63 Cf.: CARVALHO, Henrique A. D. Descripção, v.IV, p.11.

64 Cf.: CARVALHO, Henrique A. D. Descripção, v.IV, p.11-12. 